\title{
Vận dụng mô hình học tập trải nghiệm của David A. Kolb vào môn học thiết kế đồ án cho sinh viên đại học ngành kiến trúc tại Việt Nam
}

\author{
Applying David A. Kolb's experiential learning model \\ to teaching project to university architecture students in Vietnam
}

Nguyễn Hoàng Thảo Phương ${ }^{1}$, Trương Thị Như Ngọc ${ }^{2 *}$

${ }^{1}$ Trường Đại học Văn Lang, Việt Nam

${ }^{2}$ Trường Đại học Kinh Tế Thành phố Hồ Chí Minh, Việt Nam

"Tác giả liên hệ, Email: ngocttn@ ueh.edu.vn

THÔNG TIN

DOI: $10.46223 / \mathrm{HCMCOUJS.}$ tech.vi.16.1.1358.2021

Ngày nhận: 22/12/2020

Ngày nhận lại: 09/04/2021

Duyệt đăng: 15/04/2021

\section{Tù khóa:}

đồ án; David A. Kolb; học tập trải nghiệm; sinh viên kiến trúc

\section{TÓM TÁ̀T}

Mô hình học tập trải nghiệm của Kolb (1984) đã được các nhà nghiên cứu ứng dụng rất nhiều ở các môn học và ngành học khác nhau và ở nhiều cấp bậc học khác nhau. Tuy nhiên, đối với môn học Đồ án trong chương trình đào tạo bậc đại học ngành kiến trúc thì hiện nay mô hình này vẫn chưa được áp dụng rộng rãi. Do đó, bài viết này là bài viết đầu tiên đề cập chi tiết cách thức vận dụng lý thuyết của mô hình học tập trải nghiệm của Kolb vào việc xây dựng các bước thiết kế khóa học trải nghiệm, giúp nâng cao chất lượng môn học Đồ án của sinh viên ngành kiến trúc tại Việt Nam và tìm hiểu tính hiệu quả của việc áp dụng mô hình này để thiết kế một chuyến đi trải nghiệm cụ thể. Chuyến đi học tập trải nghiệm đến thành phố Đà Lạt cụ thể bao gồm 40 sinh viên đến từ ba trường đại học khác nhau, ba kiến trúc sư hàng đầu của Việt Nam và bốn Giảng viên có kinh nghiệm. Sau chuyến đi học tập trải nghiệm, sinh viên được yêu cầu chiêm nghiệm về chuyến đi và viết suy nghĩ của họ vào một trang văn bản của ứng dụng Google Docs được tạo ra cho từng cá nhân và chia sẻ trong một thư mục chung trên Google Drive cho những người tham gia. Kết quả nghiên cứu từ dữ liệu định tính thu thập ngẫu nhiên từ sự chiêm nghiệm được trình bày trên trang cá nhân Google Docs của 07 trong số 40 sinh viên tham gia chuyến đi học tập trải nghiệm cho thấy chuyến đi học tập trải nghiệm gia tăng sự hứng thú và hài lòng về việc học tập của cá nhân, tạo cảm xúc tích cực, tăng cường kỹ năng giao tiếp và networking, khả năng cảm nhận về tư duy thiết kế và nâng cao niềm tin về năng lực của bản thân.

\section{ABSTRACT}

Kolb's (1984) experiential learning model has been widely used by researchers in various disciplines for different educational levels. However, in the Project subject in the 
Keywords:

architecture students; David A.Kolb; experiential learning; project undergraduate architecture program, the current model has not been widely applied. As the first study on applying Kolb's (1984) experiential model in Project discipline for university architecture students in Vietnam, this article outlines in details how Kolb's (1984) experiential learning model can be applied to the step-bystep construction of experiential courses to improve the instructional quality of Project subject for architectural university students in Vietnam. It also examines the effects of using the experiential learning model to design a specific field trip. 40 students from three different universities, 03 architect-cum experts, and 04 experienced architecture lecturers participated in a field trip to Da Lat City as a short-term experiential learning activity. After the field trip, participant students reflected on their learning experiences by sharing their reflective thoughts in an online Google docs page created for each student in a shared Google Drive. The qualitative data results collected randomly from seven out of 40 participant students' reflection Google Docs page showed that the experiential learning increased participant students' learning interests and self-satisfaction, cultivated their positive emotions, enhanced their communication and networking skills, self-perceptions of design thinking, and improved their self-efficacy.

\section{Giới thiệu}

Môn học Đồ án là môn học đặc thù của Sinh Viên (SV) kiến trúc, chiếm vị trí quan trọng trong chương trình đào tạo kiến trúc sư xuyên suốt năm năm học. Mục tiêu dạy học môn học Đồ án hướng tới trang bị những kiến thức thiết kế kiến trúc trong nhiều thể loại công trình; có hiểu biết nhất định về công năng, thẩm mỹ và bố cục tổng mặt bằng để vận dụng trong sáng tác kiến trúc; có năng lực thiết kế và khả năng sáng tác kiến trúc; có năng lực tư duy phản biện; nâng cao kỹ năng diễn họa, thể hiện bản vẽ đồ án cũng như kỹ năng thuyết trình, thuyết phục khách hàng; qua đó hình thành và phát triển tư duy thiết kế kiến trúc cho từng công trình kiến trúc đặc thù và nâng cao ý thức đạo đức, giá trị nghề nghiệp cho SV kiến trúc. Để thực hiện nhiệm vụ này, các Giảng Viên $(\mathrm{GV})$ cần quan tâm đến vấn đề triển khai, vận dụng các triết lý thiết kế, phương pháp và hình thức tổ chức dạy học theo hướng tập trung vào người học, tạo mọi cơ hội và điều kiện để người học được trải nghiệm các không gian thực tế của từng thể loại công trình, hiểu được quy trình thiết kế, dây chuyền công năng, thẩm mỹ của công trình, giúp nâng cao chất lượng của một Đồ án thiết kế. Một trong những chiến lược phát huy được vai trò tự giác, tự lực của SV, tạo nguồn cảm hứng sáng tác, hình thành và mở rộng tư duy thiết kế, khả năng thiết kế của SV một cách tốt nhất là dạy học theo phương thức học tập trải nghiệm.

Mô hình học tập trải nghiệm của Kolb đã được áp dụng rộng rãi trong giáo dục trên thế giới (Chiu \& Lee, 2019) cũng như cho các môn học đa dạng khác nhau ở Việt nam như toán (e.g., Bui, 2020; Tang \& Pham, 2020), hóa học (e.g., T. T. T. Nguyen, 2019; Vu, Nguyen, \& Phan, 2019), vật lý (e.g., T. D. Nguyen \& Nguyen, 2016), sinh học (e.g., Tran, 2017) và ở các cấp khác nhau như trung học phổ thông (e.g., Dao \& Nguyen, 2018; T. T. T. Nguyen, 2019; Tang \& Pham, 2020; Tran, 2017) và đại học (e.g., Bui, 2020; P. T. N. Nguyen, 2018). Tuy nhiên cho đến hiện nay vẫn chưa có bài viết nào đề cập đến việc ứng dụng mô hình học tập trải nghiệm 
vào trong việc giảng dạy ngành kiến trúc tại Việt Nam. Do đó, bài viết này đề cập một số vấn đề cơ bản về mô hình học tập trải nghiệm của Kolb (nhà lý luận giáo dục tiêu biểu Hoa Kỳ), qua đó bước đầu vận dụng các giai đoạn trong mô hình này vào dạy học môn học Đồ án cho SV ngành kiến trúc tại Việt Nam. Bài viết này là một phần của dự án nghiên cứu mô hình học tập trải nghiệm của SV Khoa Kiến Trúc tại một số trường đại học ở Việt Nam. Bài viết này là nghiên cứu đầu tiên về vấn đề áp dụng mô hình Kolb và tìm hiểu tính hiệu quả của việc vận dụng mô hình này vào thiết kế một chuyến đi trải nghiệm cụ thể nhằm nâng cao chất lượng và đổi mới phương pháp giảng dạy môn học Đồ án cho SV ngành kiến trúc tại Việt Nam. Thêm vào đó, bài viết cũng đóng góp vào việc tìm hiểu cách thức vận dụng mô hình học tập trải nghiệm cho các GV ngành kiến trúc và người lập chương trình đào tạo kiến trúc để tăng hiệu quả học tập cho người học.

\section{Mô hình học tập trải nghiệm của Kolb (1984)}

Chu trình học tập trải nghiệm của Kolb (1984) vẫn là mô hình lý thuyết học tập trải nghiệm có ảnh hưởng và được trích dẫn rộng rãi nhất (Seaman, Brown, \& Quay, 2017). Kolb (1984) đưa ra giả thuyết về mô hình học tập trải nghiệm vào năm 1984 và kể từ đó ông tiếp tục xây dựng mô hình này.

Mô hình này được mô tả như một chu trình học tập lý tưởng mà người học phải trải qua tất cả các giai đoạn: trải nghiệm, phản ánh, suy nghĩ và hành động vốn có liên quan đến tình huống học tập và môn học. Tuy nhiên, việc học tập chỉ hiệu quả khi người học có thể thực hiện tất cả bốn giai đoạn của mô hình, và không có giai đoạn nào của chu trình có hiệu quả tương đương cả chu trình học tập. Kolb thừa nhận rằng ông đã tham khảo lý thuyết trong các công trình nghiên cứu của các học giả nổi tiếng thế kỷ 20 như Kurt Lewin, John Dewey và Jean Piaget và cố gắng tích hợp các chủ đề chung trong tác phẩm của họ vào một khuôn khổ hệ thống có thể giải quyết các vấn đề của thế kỷ XXI về học tập và giáo dục (Kolb, 1984). Chu trình học tập trải nghiệm 04 bước được mô tả trong Hình 1.



Khái niệm hóa trừru tương

liên quan đến bối cảnh cự thể

Hình 1. Mô hình học tập trải nghiệm của Kolb (Morris, 2019) 
Giai đoạn một (kinh nghiệm cụ thể), bắt nguồn từ kinh nghiệm học tập cụ thể (concrete experience), người học kết hợp kinh nghiệm học tập trước đó và gắn liền kinh nghiệm học tập này với bối cảnh học tập hiện tại.

Giai đoạn hai, giai đoạn quan sát phản ánh (reflective observation), người học sử dụng kinh nghiệm đã có của mình xử lí các hoạt động học tập đang xảy ra và phản hồi bằng cách suy ngẫm hoặc chia sẻ, thảo luận quan điểm với người học khác.

Giai đoạn ba - giai đoạn khái niệm hóa trừu tượng (abstract conceptualization), người học thông qua sự phân tích tư duy những khái niệm, hành động dựa trên sự hiểu biết về tình huống để trừu tượng hóa các kiến thức và kinh nghiệm mới.

Giai đoạn bốn - giai đoạn thực hành chủ động (active experimentation), người học áp dụng kinh nghiệm và sử dụng kiến thức có được để vận dụng xử lý các tình huống học tập mới.

\section{Phương pháp ứng dụng các giai đoạn trong mô hình học tập trải nghiệm của Kolb vào thiết kế, tổ chức hoạt động trải nghiệm trong môn học Đồ án}

Dựa vào mô hình học tập trải nghiệm của Kolb (1984) và cách thức vận dụng mô hình học tập trải nghiệm ở các nghiên cứu trước của Việt Nam (e.g., Dang \& Nguyen, 2017; Dao \& Nguyen, 2018) cùng với kinh nghiệm tổ chức các chuyến đi trải nghiệm thực tế cho $\mathrm{SV}$, nhà nghiên cứu đưa ra các hướng dẫn như sau:

\subsection{Dụa vào mục tiêu tùng môn học trong hệ thống Đồ án kiến trúc mà xây dụng chưong trình trải nghiệm cụ thể}

Hệ thống môn học Đồ án thuộc nhóm Kiến thức chuyên ngành, là môn học đặc thù của SV kiến trúc, với 05 năm học gồm chín học kỳ và một học kỳ Đồ án tốt nghiệp. Mỗi năm gồm 02 học kỳ, cụ thể: học kỳ 01 gồm hai Đồ án, mỗi Đồ án hai tín chỉ; học kỳ 02 gồm hai Đồ án, mỗi Đồ án hai tín chỉ; học kỳ 03 gồm hai Đồ án, mỗi Đồ án hai tín chỉ; học kỳ 04 gồm ba Đồ án, hai Đồ án hai tín chỉ và một Đồ án một tín chỉ; học kỳ 05 gồm hai Đồ án, mỗi Đồ án hai tín chỉ; học kỳ 06 gồm ba Đồ án, hai Đồ án hai tín chỉ và một Đồ án một tín chỉ; học kỳ 07 gồm hai Đồ án, một Đồ án hai tín chỉ và một Đồ án ba tín chỉ; học kỳ 08 gồm bốn Đồ án, hai Đồ án hai tín chỉ, một Đồ án một tín chỉ và một Đồ án ba tín chỉ; học kỳ 09 gồm hai Đồ án, một Đồ án ba tín chỉ và một Đồ án hai tín chỉ; và một học kỳ làm Đồ án tốt nghiệp. Từng đồ án có mục tiêu kiến thức rõ ràng nhằm mang lại kết quả tốt nhất cho $\mathrm{SV}$ sau mỗi Đồ án.

Ở giai đoạn này, GV lên chương trình trải nghiệm dựa vào mục tiêu học tập của từng môn Đồ án, có thể kết hợp hai hay nhiều Đồ án môn học trong một chương trình trải nghiệm thực tế. $\mathrm{GV}$ cần tổ chức cho $\mathrm{SV}$ tham gia vào hoạt động cụ thể/bối cảnh cụ thể nhằm khai thác những kinh nghiệm đã có của $\mathrm{SV}$, kết nối với bối cảnh mới. Hoạt động/bối cảnh có thể là một câu chuyện về tư duy thiết kế, một bản vẽ thiết kế của một kiến trúc sư, hoặc lớn hơn nữa là một chuyến tham quan công trình liên quan đến bài học. Hoạt động/bối cảnh trải nghiệm được lựa chọn và thiết kế sao cho người học phải sử dụng, khai thác và kết nối được kinh nghiệm cũ với bối cảnh mới, khơi dậy được cảm xúc, tư duy độc lập, sáng tạo của $\mathrm{SV}$.

\subsection{Tiến hành khảo sát, đánh giá nhũng địa điểm tham quan, xác định thành phần tham gia huớng dẫn để chuẩn bị cho chuơng trình trải nghiệm thục tế (Trải nghiệm cụ thể)}

Sau khi xây dựng chương trình trải nghiệm hoàn chỉnh dựa vào mục tiêu của môn học Đồ án, $\mathrm{GV}$ cần tiến hành bước khảo sát, đánh giá các địa điểm tham quan trước khi đưa $\mathrm{SV}$ đến trải nghiệm thực tế và xác định chuyên gia/người hướng dẫn chính. GV đánh giá các yếu tố tại thực địa tác động thế nào đến các hoạt động trải nghiệm của SV như: điều kiện giao thông, điều kiện 
kinh tế, môi trường xung quanh, không gian kiến trúc, con người tại bối cảnh ... Nếu có một hay hai yếu tố làm gián đoạn đến quá trình học tập trải nghiệm của SV thì GV phải chủ động thay đổi bối cảnh hoặc tình huống thực tế để hoàn thành mục tiêu ban đầu của chương trình. GV cũng có thể làm điều ngược lại là dựa vào bối cảnh thực tế mà thay đổi mục tiêu ban đầu của chương trình trải nghiệm, kết hợp thêm các mục tiêu của môn học Đồ án khác nhằm đem lại một chương trình trải nghiệm hoàn hảo cho $\mathrm{SV}$. Thêm vào đó, việc mời chuyên gia/GV hướng dẫn chính cũng là một yếu tố quan trọng trong chương trình trải nghiệm. Chuyên gia/GV hướng dẫn là người tạo cảm hứng, khơi ngợi, dẫn dắt và cung cấp cho $\mathrm{SV}$ những kinh nghiệm thực tế, chuyên sâu về đề tài.

\subsection{Tổ chức quan sát, đối chiếu, phản hồi, xủ̉ lý trải nghiệm (Quan sát, phản ánh)}

Đây là giai đoạn SV trực tiếp tham gia vào hoạt động cụ thể, tương tác trực tiếp với môi trường học tập; đồng thời SV quan sát, đối chiếu các sự vật, hiện tượng, phân tích, đánh giá, tổng hợp, thường xuyên đặt câu hỏi, huy động vốn kinh nghiệm của bản thân để hiểu về sự vật, hiện tượng và tìm ra phương án trả lời phù hợp. Tùy từng thể loại đồ án, việc tổ chức quan sát/xử lý trải nghiệm có thể diễn ra theo các cách sau: SV tìm hiểu bản chất hoạt động, tình huống mà họ vừa tham gia; quan sát, xem xét, suy ngẫm, chiêm nghiệm về những hoạt động, hiện tượng đã trải qua; đưa ra các dự đoán cái gì đã diễn ra và cái gì sẽ diễn ra trong tình huống tương tự; tìm hiểu, thử nghiệm cách thức tiến hành hoạt động, tìm ra nguyên lý của hoạt động; liên hệ với những kinh nghiệm đã có, có khả năng suy nghĩ có phê phán.

\subsection{Tổng quát/khái quát hóa (Khái niệm hóa, trùu tự̣ng hóa)}

Đây là bước đánh dấu sự trưởng thành trong nhận thức của SV. SV hình thành những kinh nghiệm mới dưới dạng kiến thức mới, kỹ năng mới, thái độ mới và giá trị mới dưới các hình thức khác nhau: chia sẻ bằng lời, bài thuyết trình, bài viết ngắn, bài luận, bài thu hoạch, sản phẩm của môn học và các sáng tác. Yêu cầu $\mathrm{SV}$ miêu tả những điều đã trải nghiệm, phân tích những ý nghĩa của các trải nghiệm đó cho bản thân; từ đó khái quát hóa các khái niệm trừu tượng liên quan đến bối cảnh cụ thể, đồng thời khái quát hóa kết quả trải nghiệm thu được để đúc kết thành kiến thức của riêng mình.

\section{5. Úng dụng/thử nghiệm tích cụcc (thục hành chủ động)}

Bước này yêu cầu $\mathrm{SV}$ nêu cách thức áp dụng những điều vừa mới học vào thực hiện các nhiệm vụ học tập thực tế hoặc chủ động vận dụng, thực hành nâng cao hiệu quả kiến thức đó trong một tình huống học tập mới với những điều kiện khác nhau nhằm mở rộng tri thức, chú trọng tính thực hành vận dụng, chủ động đưa ra các quyết định, các cách giải quyết vấn đề. Ở giai đoạn này, $\mathrm{SV}$ chú trọng vào thực hành vận dụng, hoàn toàn chủ động trong các quyết định của mình, thử nghiệm các phương án giải quyết vấn đề, ra quyết định. Yêu cầu SV nêu cách thức áp dụng những điều vừa mới học vào thực hiện các nhiệm vụ học tập thực tế hoặc chủ động vận dụng, thực hành nâng cao hiệu quả kiến thức đó trong một tình huống học tập mới với những điều kiện khác nhau nhằm mở rộng tri thức, chú trọng tính thực hành vận dụng, chủ động đưa ra các quyết định, các cách giải quyết vấn đề.

4. Minh họa cụ thể về việc ứng dụng các giai đoạn trong mô hình học tập trải nghiệm của Kolb (1984) để xây dụng chương trình trải nghiệm thực tế phục vụ cho môn học Đồ án của ngành Kiến trúc

\subsection{Xây dụng mục tiêu chương trình trải nghiệm thục tế dụa vào mục tiêu môn học Đồ án kiến trúc tại truờng đại học}

Trong chương trình đào tạo kiến trúc sư Khóa 25 của Khoa kiến trúc ĐH Văn Lang, 
trong hệ thống môn học đồ án GV chọn kết hợp ba môn học Đồ án: Bài tập (Đồ án) cơ sở 02 (hai tín chỉ, học kỳ 01 , năm 01), Thiết kế nhanh 01 (một tín chỉ, học kỳ 04 , năm 02), Đề cương và chọn đề tài tốt nghiệp (hai tín chỉ, học kỳ 09, năm 05) để xây dựng chương trình học tập trải nghiệm tại Đà lạt cho $\mathrm{SV}$. Dựa vào các mục tiêu cụ thể của từng môn học, $\mathrm{GV}$ áp dụng quy trình học tập trải nghiệm của Kolb (1984) để xây dựng mục tiêu cho chương trình trải nghiệm thực tế như sau (Bảng 1).

\section{Bảng 1}

So sánh mục tiêu học tập của các môn học Đồ án tại trường và mục tiêu học tập của chương trình học tập trải nghiệm thực tế

\begin{tabular}{|c|c|c|}
\hline & $\begin{array}{r}\text { trường khi } \\
\text { hình học tậ } \\
\text { DaI }\end{array}$ & $\begin{array}{l}\text { rình trải nghiệm } \\
\text { nô hình học tập } \\
\text { avid A. Kolb }\end{array}$ \\
\hline & $\begin{array}{l}\text { - SV có kiến } \\
\text { bản vẽ đồ án } \\
\text { - SV có kỹ nă } \\
\text { đồ án thiết ké }\end{array}$ & \multirow{3}{*}{ 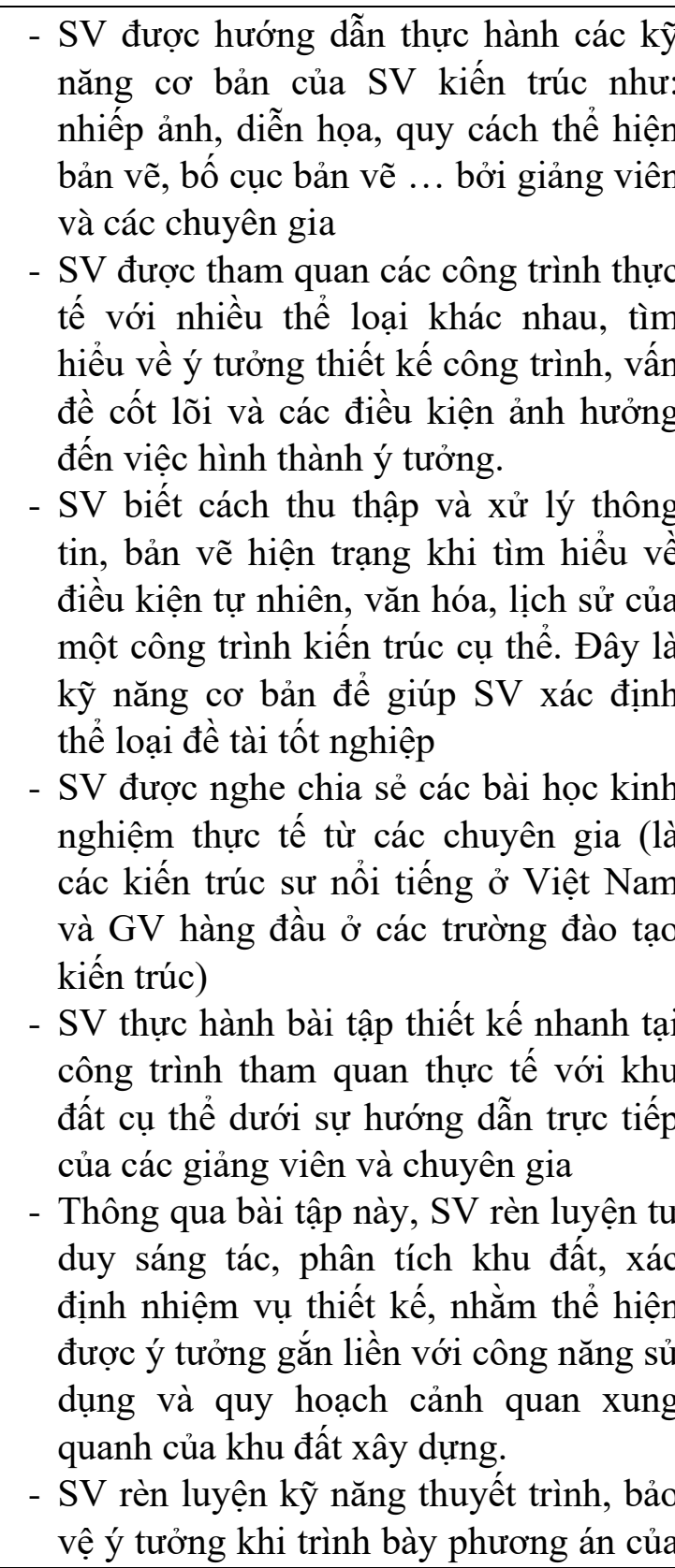 } \\
\hline & $\begin{array}{l}\text { - SV rèn luyệ1 } \\
\text { kiến trúc } \\
\text { - Nắm bắt đượ } \\
\text { cốt lõi, quan } \\
\text { tài, từ đó đưa } \\
\text { kế ý tưởng so } \\
\text { - Trang bi kỹ } \\
\text { thể hài hòa } \\
\text { không gian cố } \\
\text { - Trang bị kỹ } \\
\text { cục và trình } \\
\text { được hiệu qu } \\
\text { án }\end{array}$ & \\
\hline & $\begin{array}{l}\text { - Hiểu biết chuyê } \\
\text { loại công trình } \\
\text { xác định đúng t } \\
\text { công trình và } \\
\text { diện vị trí khu đ } \\
\text { - Rèn luyện kỹ } \\
\text { thông qua phân } \\
\text { xác định nhiệm } \\
\text { - Ý thức được } \\
\text { nghiên cứu về } \\
\text { trình, quy mô } \\
\text { điểm khu đất } \\
\text { khi bắt đầu qu } \\
\text { kiến trúc }\end{array}$ & \\
\hline
\end{tabular}




\begin{tabular}{|c|c|c|}
\hline So sánh & $\begin{array}{c}\text { Mục tiêu của môn học đồ án tại } \\
\text { trường khi chưa áp dụng mồ } \\
\text { hình học tập trải nghiệm của } \\
\text { David A. Kolb }\end{array}$ & $\begin{array}{c}\text { Mục tiêu của chương trình trải nghiệm } \\
\text { thực tế khi áp dụng mô hình học tập } \\
\text { trải nghiệm của David A. Kolb }\end{array}$ \\
\hline \multirow{2}{*}{$\begin{array}{c}\text { lựa chọn đề tài tốt nghiệp phù } \\
\text { hợp khả năng }\end{array}$} & $\begin{array}{c}\text { bài tập thiết kế nhanh với các chuyên } \\
\text { gia }\end{array}$ \\
& $\begin{array}{c}\text { SV có điều kiện thảo luận, trao đổi trực } \\
\text { tiếp, đặt câu hỏi, phản hồi, đưa ra các ý } \\
\text { tưởng mới, khái niệm mới, cùng các } \\
\text { chuyên gia }\end{array}$ \\
\hline
\end{tabular}

Nguồn: Đại Học Văn Lang (n.d.), Pham (2020)

\subsection{Xác định thành phần tham gia}

Lý thuyết của Kolb là "lấy người học làm trung tâm”, GV chỉ đóng vai trò tổ chức, tạo ra những trải nghiệm phù hợp với mục tiêu chương trình. Tuy nhiên, nhằm nâng cao tính thực hành, tính trải nghiệm chuyên sâu cho $\mathrm{SV}$ thì sự tham gia hướng dẫn của các kiến trúc sư nổi tiếng từ các doanh nghiệp, các chuyên gia hàng đầu trong lĩnh vực đào tạo kiến trúc là không thể thiếu, là chất xúc tác quan trọng, mang tính định hướng, dẫn dắt, một phần tạo nên thành công của chương trình trải nghiệm. GV cần lên kế hoạch và trao đổi trực tiếp với các khách mời về mục tiêu, nội dung của chuyến học tập trải nghiệm. Hai bên thống nhất kế hoạch chung về lịch trình, vai trò, nội dung chia sẻ, các bài học kinh nghiệm và các bài tập thực hành. Do đó, ngoài $\mathrm{SV}$, thành phần tham gia quan trọng trong chuyến đi học tập trải nghiệm là các chuyên gia, kiến trúc sư nổi tiếng và $\mathrm{GV}$ có kinh nghiệm để hướng dẫn chính cho $\mathrm{SV}$ các nội dung học tập trải nghiệm. Cụ thể như sau: một chuyên gia phụ trách hướng dẫn phát triển ý tưởng thiết kế, một chuyên gia phụ trách hướng dẫn ký họa, một chuyên gia phụ trách hướng dẫn kỹ năng nhiếp ảnh trong lĩnh vực kiến trúc, một $\mathrm{GV}$ phụ trách hướng dẫn quy hoạch, một GV phụ trách hướng dẫn văn hóa, lịch sử. Thêm vào đó là hai $\mathrm{GV}$ chịu trách nhiệm lên kế hoạch và tổ chức các hoạt động trải nghiệm cho $40 \mathrm{SV}$ kiến trúc đến từ thành phố Hồ Chí Minh $(30 \mathrm{SV}$ từ khoa kiến trúc ĐH Văn Lang, $05 \mathrm{SV}$ từ ĐH Kiến Trúc, và $05 \mathrm{SV}$ từ ĐH Tôn Đức Thắng). Để đảm bảo tính bảo mật cá nhân, tên của $S V$ tham gia đã được thay đổi và tên của $G V$ tham gia trong phần chiêm nghiệm mà SV đề cập đã được thay bằng từ viết tắt.

\subsection{Nội dung tiến hành}

Chuyến đi học tập trải nghiệm đến Đà Lạt diễn ra trong bốn ngày và ba đêm.

- Ngày 01 (Bắt đầu chuyến đi đến địa điểm Núi Hòn Bồ).

Mục tiêu: Kết nối và tạo cảm xúc.

\section{Nội dung trải nghiệm:}

$\checkmark$ Leo núi, cắm trại trên núi, đón bình minh, săn mây;

$\checkmark$ Kỹ năng sinh tồn giữa núi rừng;

$\checkmark$ Quy hoạch Đà Lạt xưa và nay;

$\checkmark$ Các phương pháp thu thập dữ liệu và xử lý thông tin.

- Ngày 02 (Địa điểm: Nhà thờ Camly và Đà Lạt Cadasa Resort).

Mục tiêu: Tham quan công trình thực tế và thực hành các kỹ năng.

Nội dung trải nghiệm: 
$\checkmark$ Tìm hiểu về giá trị lịch sử, văn hóa của công trình;

$\checkmark$ Bài học về việc khai thác tính truyền thống trong thiết kế công trình kiến trúc đương đại;

$\checkmark$ Kỹ năng ký họa giúp thể hiện ý tưởng nhanh;

$\checkmark$ Kỹ năng nhiếp ảnh trong kiến trúc.

- Ngày 03 (Địa điểm: Nhà thờ Kadon).

Mục tiêu: Tham quan công trình thực tế đạt giải thưởng kiến trúc và thực hành bài tập thiết kế nhanh.

Nội dung trải nghiệm:

$\checkmark$ Phân tích các yếu tố về quy hoạch, lịch sử, văn hóa tác động đến ý tưởng thiết kế công trình;

$\checkmark$ Phương pháp hình thành ý tưởng, tư duy thiết kế cho một đề tài;

$\checkmark$ Thực hành thiết kế nhanh tại công trình thực tế;

$\checkmark$ Thực hành kỹ năng thuyết trình bảo vệ phương án;

$\checkmark$ Đêm gala trao giải và trao chứng nhận chuyến học trải nghiệm.

- Ngày 04 (Địa điểm: Lê Homestay).

Mục tiêu: Tổng kết đánh giá và kết thúc chuyến đi.

Nội dung trải nghiệm:

$\checkmark$ Gắn kết, chia sẻ những bài học đã học được;

$\checkmark$ Rút ra được các kiến thức mới ứng dụng cho tương lai.

\subsection{Câu hỏi nghiên cứu:}

Kinh nghiệm của SV khi tham gia chương trình học tập trải nghiệm ngắn hạn là gì?

\subsection{Phưong pháp nghiên cúu}

Sau chuyến đi học tập trải nghiệm, $S V$ được yêu cầu viết cảm nhận của cá nhân và chiêm nghiệm về trải nghiệm của họ trong nhật ký trải nghiệm chuyến đi thực tế. Do đó, nhà nghiên cứu sử dụng dữ liệu định tính thu thập ngẫu nhiên từ 07 trong số 40 nhật ký trải nghiệm của $\mathrm{SV}$.

\subsection{Phwơng pháp phân tích}

Dữ liệu định tính được phân tích theo phương pháp phân tích nội dung quy nạp. Dữ liệu được thu thập, và phân tích bằng cách sử dụng các hướng dẫn phân tích nội dung quy nạp do Marshall và Rossman (2014) đề xuất. Nhà nghiên cứu sắp xếp dữ liệu định tính thông qua mã hóa mở và tạo các danh mục trừu tượng hóa. Theo đó, nhà nghiên cứu đã làm rõ nội dung bằng cách viết các ghi chú và đề mục trong văn bản trong quá trình đọc đi đọc lại. Sơ đồ mã hóa cuối cùng bao gồm các mã dựa trên các câu hỏi nghiên cứu và khung lý thuyết và các mã quy nạp.

\subsection{Kết quả thục hiện}

Nhìn chung, SV đã có nhiều phản hồi tích cực, so sánh được những giá trị họ nhận được trước và sau khi tham gia chuyến đi học tập trải nghiệm tại Đà Lạt. Kết quả dữ liệu thu thập từ nhật ký chiêm nghiệm trên trang Google Docs của 07 cá nhân SV thu thập ngẫu nhiên trong số $40 \mathrm{SV}$ tham gia chuyến đi trải nghiệm cho thấy có năm chủ đề chính.

\subsubsection{Gia tăng sự hứng thú và hài lòng về việc học tập của bản thân}

Theo ý kiến của SV, lớp học truyền thống không mang lại cho SV sự hứng thú thật sự. 
Nhưng sau khi tham gia chuyến đi trải nghiệm, hầu như tất cả SV cảm nhận họ tiếp thu được các bài học lý thuyết khô khan một cách nhanh chóng. Ví dụ sau đây minh họa sự thay đổi này.

Bình thwờng ngồi trên lớp bàn ghế đàng hoàng máy lạnh ngút ngàn thì gục lên gục lên gục xuống... Hôm nay vìa phải dậy sơm vìa ngồi bệt dưới đất mà mặt mũi đứa nào đứa nấy sáng rực. Bài thầy giảng nghe tụ nhiên gần gũi lắm nhu người anh truyền kinh nghiệm cho mấy đứa em, nghe tới đâu thì thấm tới đó. (Thùy)

Có lẽ sự hứng thú này là do SV lần đầu được trải nghiệm học tập thực tế cùng với sự hướng dẫn tận tình của các chuyên gia, các kiến trúc sư nổi tiếng. Đây không phải là lý thuyết suông mà là những bài học kinh nghiệm sâu sắc, được đúc kết sau bao nhiêu năm hành nghề kiến trúc, mang tính ứng dụng thực hành cao.

Thầy B bắt đầu rút quyển sổ rồi kí hoa một cách xuất thần trong vòng 10 phút. Lúc này tụi mình thật sụ được trải nghiệm với việc kí hoạ. Rồi đưa nào đứa nấy háo hức lấy tập lấy bút ra ngồi hí hoáy... (Thùy)

Việc lồng ghép tình huống, có ví dụ dẫn dắt, chia sẻ các mẹo nhỏ làm cho bài học lý thuyết trở nên sinh động và dễ nhớ. Cộng với việc ứng dụng thực hành các bài tập kiến trúc tại công trình thực tế ngay sau đó, $\mathrm{SV}$ cảm thấy cách học này lôi cuốn.

Bởi thế, không đơn thuần là lý thuyết suông nghe tai này lọt tai kia, mà thông qua bài tập thiết kế nhanh ở ngày trải nghiệm thư ba, em đã thấm nhanh một khối luợng kiến thức khổng lồ. Vỏn vẹn chi trong 7 giờ đồng hồ, em đã tham gia rất nhiều hoạt động: vùa tìm hiểu tài liệ, vì̀a kí hoạ; vùa chụp ảnh; vùa nghĩ, vìa bàn cãi với nhóm vì ai cũng mong muốn ra được ý tương hay. Theo kế hoạch được tính toán vô cùng kĩ luỡng của ban tổ chức, mọi giác quan của em đều được đánh thức không chỉ với việc cảm nhận công trình mà còn với con người, thiên nhiên và văn hoá nơi đây. Đây là một trải nghiệm hoàn toàn khác xa với bài tập thiết kế nhanh ở trương. (Trinh)

Trong lớp học truyền thống SV thiếu trải nghiệm thực tế mặc dù có tự giác học tập bằng cách tham khảo các tài liệu, bản vẽ sẵn có, nhưng vẫn không thể hình dung và cảm nhận không gian kiến trúc, thiếu cảm xúc trong các thiết kế của chính mình.

Nhớ ngày xura, khi làm Thiết kế nhanh hay đồ án dù lớn hay nhỏ, mình chỉ nhận đề tài, lên mạng nghiên cưu pinterest rồi archdaily và phác ra phương án, cuối cùng hoàn thành bài mà chẳng đọng lại một xúc cảm gì. (Thân)

Trải nghiệm tham quan thực tế ngoài việc giúp cho SV cảm nhận rõ không gian chức năng từng thể loại công trình kiến trúc còn cung cấp nhiều chất liệu để hình thành nên tư duy thiết kế như yếu tố văn hóa, xã hội, điều kiện tự nhiên, bối cảnh quan xung quanh.

Sụ cảm nhận về một công trình kiến trúc: Đến các công trình chua tùng biết tới, được đặt chân vào không gian đấy, được "Chạm-ngưi-nghe-nhìn”. (Định)

Kiến trúc bản chất không đon thuần là làm thiết kế, khi chỉ tập trung thiết kế, chúng ta chỉ tập trung suy nghĩ của bản thân, mà quên mất nhũng thứ vô hình, ngườ KTS cần trải nghiệm nhiều để tăng vốn sống cho bản thân và nghĩ rộng ra cho xã hội. Kiến trúc là một ngành nhân văn, cách suy nghĩ nhân văn giúp cho thiết kế chúng ta trở nên có giá trị cho xã hội. (Thân)

\subsubsection{Tạo cảm xúc tích cục}

Lớp học kết hợp mô hình học tập trải nghiệm tạo cảm xúc tích cực và mang lại cho SV cảm hứng thiết kế và tạo động lực nỗ lực. 
Nhũng cảm xúc trong tôi thật sự trọn vẹn. Có thể nói đây một chuyến đi thực tế mang lại một sụ trải nghiệm rất đặc biệt. Tù việc gặp gõ các thầy cô đầy nhiệt huyết, gặp gỡ các bạn SV đồng hành cùng chí hướng. (Định)

Điều quan trọng trong thiết kế kiến trúc là cảm xúc, mà muốn xây dựng được cảm xúc thì phải trải nghiệm, trải nghiệm thì phải nhìn và liên tuởng tới nhũng thư mà mình đã đọc đã tìm hiểu để liên kết với nhau, tù đó cảm nhận, nghe được âm thanh mùi vị trong nhũng cái hũu hình. (Ca)

Sự tuyệt vời có lẽ với chúng mình nói riêng và tập thể nói chung đều cảm nhận được bằng trục, thính, xúc và cả vị giác. Chuyến đi "trải nghiệm" cho mình biết rằng 5 năm qua mình đã thiếu nhũng gì, nhũng cảm xúc sâu lắng đến thăng hoa trong suy tu mà riêng cá nhân đang đúng trước ngữ̛ng cửa mở ra lối đi mới được thắp sang tù nhũng ngon lưa của các thầy cô luôn cháy mà không một ngày nguội lạnh, nhũng bài học khó mà cảm thu nếu chúng ta thụ động. (Bích)

\subsubsection{Nâng cao kỹ năng giao tiếp và networking}

Việc trải nghiệm thực tế còn tạo cơ hội cho SV giao tiếp với nhau, phát triển kỹ năng giao tiếp về truyền đạt.

Chuyến đi có cả sụ góp mặt của các bạn sv kiến trúc ở ĐH TĐT và cả ĐH KT, nhũ̃ng con người xa lạ gặp được nhau trải nghiệm cùng nhau và để lại cho nhau nhũng kỉ niệm khó quên. Ai cũng bồn chồn, ai cũng tiếc nuối vội vã xin facebook nhau để mà còn liên lạc. Thật sụ chuyến đi đã mang lại rất nhiều niệm vui mới và nhũng người bạn mới. (Thùy)

Là một SV cũng khá rụt rè, nhút nhát, nên em sọ mình sẽ lẻ loi khi đến một nơi xa lạ, gặp những người xa lạ. Nhưng khi nghe các bạn nói chuyện em nhận ra là các bạn cũng chưa quen biết nhau, chi mới là thấy nhau trong trường. Và rồi khi đã lên chuyến xe thi ai cũng xem nhau nhu anh chị em trong nhà, bắt chuyện, nô đùa, làm quen cũng tù đó đến rất tụ nhiên. (Đan)

\subsubsection{Tăng cuờng khả năng cảm nhận về tu duy thiết kế của bản thân}

Trước đây SV chưa cảm nhận được bài thiết kế và không hiểu được lý do vì sao SV không hài lòng về bài thiết kế của họ. Nhưng sau chuyến đi SV đã có câu trả lời cho bản thân và nhận biết được nguyên nhân cho việc không hài lòng về bài thiết kế của họ. Đó chính là việc thiếu trải nghiệm.

Trong quá trình làm đồ án ở trường, em đã bỏ ra rất nhiều công sức, bài có đủ, có đúng, đôi khi đẹp, điểm số cũng tuoong đối, nhung em vẫn thấy thiếu thiếu, sai sai cái gì đó. Dù đầu tu chỉnh chu đến mấy, điểm tốt đến mấy, em vẫn không cảm thấy thoả mãn. Điều còn thiếu rốt cuộc là gì? Đến với chuyến trải nghiệm...em đã hiểu ra điểm "sai sai" ở đâu rồi. Chính là, em không thể "cảm” được chính thiết kế của mình ... Và nguyên nhân đơn giản thôi, bắt nguồn tù việc em thiếu trải nghiệm. Em nhận ra việc trải nghiệm quan trọng nhu thế nào, cho dù điều đó không thể thấm trong ngày một, ngày hai. Nhung nếu không có nhüng ngày đầu, sẽ không thể nào có nhüng ngày sau ... Nhũ̃ng điều trên, không phải em chua tùng tìm hiểu, chưa tùng đọc hay nghe qua. Điều cốt lõi, em có đọc nhiều đến mấy, nghe nhiều đến đâu, dù vô tình hay cố ý đưa vào tiềm thức, nhung nếu không thật sự đi trải nghiệm, toàn tâm toàn ý suy nghĩ và cảm nhận thì khó mà đánh thức bất ki điều gì. (Trinh)

4.7.5. Nâng cao niềm tin về năng lực thiết kế của bản thân 
Chuyến đi trải nghiệm thực tế ngoài việc đem lại cho SV những trải nghiệm, và cảm xúc tích cực, còn làm tăng niềm tin về năng lực thiết kế của bản thân $\mathrm{SV}$.

Bản thân em cũng không thật sụ tin tuởng khả năng của mình, đặc biệt khi đối diện với đề bài hóc búa và áp lực về thời gian. Nhưng trong cái khó thì mới ló cái khôn, nên thạt sụ bất ngò̀, chúng em không chỉ hoàn thành bài tập, mà còn vượt cả sư mong đợi của tất cả mọi người. Riêng bản thân em, chính nhũng lúc căng thẳng nhất, khi đầu trống rống trước một tờ giấy trắng, thì chính áp lực và cảm xúc dâng trào là lúc em nghe âm vang tiếng hát thánh ca của nhũng đứa trẻ hoà vào tiếng gió) đã đẩy em bật ra được ý tuởng. (Trinh)

\section{Thảo luận và Kết luận}

Nhìn chung, kết quả nghiên cứu từ dữ liệu định tính thu thập sau chuyến đi học tập trải nghiệm của $\mathrm{SV}$ tham gia cho thấy một sự thay đổi tích cực trong hứng thú học tập, sự hài lòng về học tập của cá nhân, cảm xúc trong thiết kế, khả năng cảm nhận về tư duy thiết kế. Ngoài ra, SV còn thể hiện sự cải thiện trong một số kỹ năng mềm như kỹ năng giao tiếp và networking. Quan trọng hơn nữa là, $\mathrm{SV}$ còn được nâng cao niềm tin về năng lực thiết kế của bản thân, vốn là yếu tố quan trọng để thúc đẩy SV đạt được kết quả học tập như mong đợi.

Do đó, khi thiết kế các hoạt động dạy học theo mô hình học tập trải nghiệm, GV cần cân nhắc rằng, học tập trải nghiệm phải là một quá trình liên tục, dựa vào kinh nghiệm cá nhân của SV và đảm bảo SV phải trải qua tất cả các giai đoạn trong chu trình học tập trải nghiệm. Bên cạnh đó, thiết kế các hoạt động trải nghiệm phải đánh thức được tất cả các giác quan của người học để tương tác trực tiếp với sự vật, hiện tượng, với không gian kiến trúc, con người và bối cảnh của từng thể loại công trình. Ngoài ra, GV nên khuyến khích SV khái quát hóa, đưa ra khái niệm mới, kinh nghiệm mới dựa trên kinh nghiệm cá nhân khi tương tác với sự vật, hiện tượng, cho dù là chính xác hay chưa chính xác. Những kinh nghiệm mới này của $\mathrm{SV}$ sẽ tạo thành tình huống có vấn đề, kích thích SV tham gia trải nghiệm, thử nghiệm tích cực.

Hơn nữa, lý thuyết của Kolb là "lấy người học làm trung tâm", nên GV cần lưu ý rằng những trải nghiệm được thiết kế yêu cầu $\mathrm{SV}$ trở thành người khởi xướng, đưa ra quyết định và chịu trách nhiệm về kết quả đạt được. Vai trò cơ bản của $G V$ bao gồm việc tạo ra những trải nghiệm thích hợp, đặt ra vấn đề, đưa ra những ranh giới, hỗ trợ sinh viên, đảm bảo sự an toàn về cảm xúc và thể chất, và tạo điều kiện thúc đẩy quá trình học tập. $\mathrm{GV}$ và $\mathrm{SV}$ sẽ có khả năng được trải nghiệm những thành công, thất bại, khám phá và chấp nhận rủi ro. GV cần nhận ra và thúc đẩy những cơ hội tự nhiên xảy đến cho quá trình học tập, những cơ hội này có thể là hậu quả của những sai lầm hay bài học từ những thành công, từ đó xây dựng, thiết kế nội dung học tập trải nghiệm một cách linh hoạt và sáng tạo hơn.

Việc vận dụng các giai đoạn trong mô hình học tập trải nghiệm của Kolb (1984) vào dạy học môn học Đồ án của SV kiến trúc tại các trường đại học sẽ góp phần nâng cao chất lượng đào tạo $\mathrm{SV}$ một cách bền vững, nhấn mạnh việc học tập là một quá trình liên tục, "lấy người học làm trung tâm", tư duy thiết kế của SVdựa trên những kinh nghiệm đã có đặt trong sự tương tác với tình huống mới, $\mathrm{SV}$ đối chiếu và tự hình thành tri thức cho bản thân, kiến thức được kiến tạo thông qua sự chuyển đổi kinh nghiệm. Vì vậy, dạy học theo mô hình học tập trải nghiệm đòi hỏi GV phải tổ chức các hoạt động trải nghiệm sao cho mỗi SV thực sự được trải nghiệm trong môi trường thực tế của từng thể loại công trình. Ngoài ra, GV xây dựng tiến trình trải nghiệm phải phát huy được tối đa kinh nghiệm cá nhân của $\mathrm{SV}$, tương tác trực tiếp với không gian, với con người, sự vật, hiện tượng để tự kiến tạo nên tri thức cho mỗi cá nhân.

Song, các tri thức đó phải được SV vận dụng một cách sáng tạo trong việc thiết kế Đồ án 
tại trường đại học trong các tình huống khác nhau để SV tự mình đối chiếu, chiêm nghiệm, củng cố, mở rộng, nâng cao hơn vốn kinh nghiệm thiết kế, hình thành triết lý thiết kế kiến trúc mới cho bản thân. Do đó, các bước thiết kế và tổ chức hoạt động trong bài viết này là những gợi ý có tính chất định hướng, không phải là quy trình cứng nhắc. Việc thiết kế và tổ chức hoạt động trải nghiệm trong các thể loại công trình cần linh hoạt, sáng tạo phù hợp với $\mathrm{SV}$, mục tiêu học tập, điều kiện của Nhà trường và địa phương. Quan trọng nhất là phải đảm bảo các điểm trọng tâm của học tập trải nghiệm như trải nghiệm cụ thể (đảm bảo có sự kết nối giữa kinh nghiệm cũ và kinh nghiệm mới), phản hồi kinh nghiệm (qua hoạt động, sinh viên phải được quan sát, suy ngẫm, phân tích, liên hệ, suy luận, chiêm nghiệm), khái quát hóa thành kiến thức mới của bản thân, vận dụng trong bối cảnh mới. Các nghiên cứu trong tương lai cần quan tâm đến các yếu tố này khi vận dụng mô hình học tập trải nghiệm để thiết kế hoạt động trải nghiệm hiệu quả cho SV kiến trúc trong và ngoài nước.

\section{Tài liệu tham khảo}

Bui, M. T. T. (2020). Vận dụng mô hình học trải nghiệm để nâng cao kỹ năng sư phạm cho SV thông qua học phần thực hành dạy học toán [Applying experiential learning model to improve pedagogical skills for students through the practical module of teaching mathematics]. Tạp chí khoa học trường Đại học Su phạm thành phố Hồ Chí Minh, 17(5), 775 -784.

Chiu, S. K., \& Lee, J. (2019). Innovative experiential learning experience: Pedagogical adopting Kolb's learning cycle at higher education in Hong Kong. Cogent Education, 6(1), 1-16.

Đại Học Văn Lang. (n.d.). Quyết định ban hành chuoong trình đào tạo [Decision to issue training program]. Retrieved February 10, 2021, from http://kientruc.vlu.edu.vn/nganh-kien-truc

Dang, M. T. T., \& Nguyen, T. V. (2017). Vận dụng mô hình học tập trải nghiệm trong dạy học sinh học ở trường trung học cơ sở [Applying experiential learning model in teaching students to learn in junior high school]. Tạp chí Giáo dục, (No. Special), 89-92.

Dao, M. T. N., \& Nguyen, H. T. (2018). Học tập trải nghiệm-Lí thuyết và vận dụng vào thiết kế, tổ chức, hoạt động trải nghiệm trong môn học ở trường phổ thông [Experiential learningTheory and application to design, organization, and experiential activities in high school subjects]. Tạp chí Giáo duc, 433(1), 36-40.

Kolb, D. A. (1984). Experiential learning: Experience as the source of learning and development (2nd ed.). Upper Saddle Silver, NJ: Pearson FT Press.

Marshall, C., \& Rossman, G. B. (2014). Designing qualitative research. London, UK: Sage.

Morris, T. H. (2019). Experiential learning - A systematic review and revision of Kolb's model. Interactive Learning Environments, 28(8), 1-14. doi:10.1080/10494820.2019.1570279

Nguyen, D. T., \& Nguyen, H. V. (2016). The use of experiential learning in teaching physics. UTEHY Journal of Science and Technology, 12, 143-149.

Nguyen, P. T. N. (2018). Thực trạng tổ chức dạy học trải nghiệm của GV Khoa Sư phạm, Trường ĐH Cần Thơ [Reality of organization of experiential teaching of teachers of Faculty of Pedagogy, Can Tho University]. Tạp chi Khoa học trường Đại học Cần Tho', 54(9), 104-112.

Nguyen, T. T. T. (2019). Quy trình thiết kế và tổ chức dạy học các chủ đề trải nghiệm trong môn hóa học [The process of designing and organizing teaching of experiential topics in 
chemistry]. Tạp chí khoa học - Đại học Huế: Xã hội nhân văn, 128(6A), 29-41.

Pham, C. (2020). Sinh viên kiến trúc ĐH Văn Lang tham gia tour kiến trúc trải nghiệm tại Đà Lạt [Architecture students of Van Lang University participate in an experiential architecture tour in Da Lat]. Retrieved February 12, 2021, from https:/www.vanlanguni.edu.vn/hoatdong-sinh-vien/2210-sinh-vien-kien-truc-dh-van-lang-tham-gia-tour-kien-truc-trai-nghiemtai-da-lat

Seaman, J., Brown, M., \& Quay, J. (2017). The evolution of experiential learning theory: Tracing lines of research in the JEE. Journal of Experiential Education, 40(4), 1-20.

Tang, D. M., \& Pham, M. K. (2020). Mô hình học tập trải nghiệm Kolb: Dạy học trường hợp đồng dạng cạnh-cạnh-cạnh của hai tam giác [Kolb experiential learning model: Teaching the case of side-by-side congruence of two triangles]. Tạp chi KHoa hoc truòng Đại hoc Su pham thành phố Hồ Chí Minh, 17(5), 766-774.

Tran, G. T. (2017). Applying experiential learning Kolb's model into designing "experiential learning cycle" in teaching biology in general school. VNU Journal of Science: Education Research, 33(3), 1-6.

Vu, L. P., Nguyen, V. T. P., \& Phan, L. T. Q. (2019). Building assessment toolkit to assess collaborative problem solving competence through teaching chemistry of the non-metals. VNU Journal of Science: Education Research, 35(4), 112-126. 